ISSN 2620-6760, Vol. 1, No. 1, April 2018

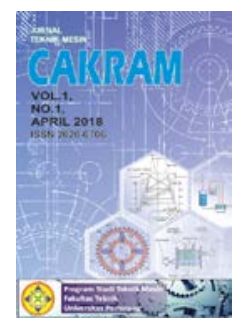

\title{
UJI KALIBRASI (KETIDAKPASTIAN PENGUKURAN) TIMBANGAN DIGITAL MENGACU PADA STANDAR JCGM 100:2008
}

\author{
Joko Setiyono $^{1}$ \\ ${ }^{1}$ Program Studi Teknik Mesin, Universitas Pamulang, Jl. Surya Kencana No. 1, Tangerang Selatan, Indonesia \\ E-mail : jojosetiyono@yahoo.co.id
}

Masuk : 5 Maret 2018

Direvisi : 20 Maret 2018

Disetujui :27 Maret 2018

\begin{abstract}
Abstrak: Timbangan digital merupakan salah satu instrument yang banyak digunakan di setiap posyandu studi kasus kali ini terjadi di Posyandu Puri Permata Bogor. Dengan kapasitas $10 \mathrm{~kg}$ dengan akurasi 0,005 kg yang sering digunakan untuk menimbang balita warga. Akan tetapi tidak pernah dilakukan pengujian kalibrasi dan verifikasi kinerja secara berkala, sehingga akurasinya perlu dipertanyakan. Oleh karena itu dalam penelitian ini telah dicoba dilakukan uji kalibrasi dan pengukuran ketidakpastian pengukuran dari timbangan digital tersebut. Uji kalibrasi meliputi kemampuan baca timbangan, daya ulang pembacaan timbangan, penyimpangan dari nilai skala nominal, serta diuji pengaruh posisi pembebanan tidak terpusat. Dari hasil kalibrasi diperoleh bahwa timbangan Seca mempunyai nilai koreksi terendah 4,9 gram pada nominal pembebanan 1.000 gram dan tertinggi 45 gram pada nominal pembebanan 10.000 gram. Nilai ketidakpastian pengukuran $\pm 4,22$ gram dan pada uji pengaruh posisi pembebanan tidak terpusat mendapat nilai maksimum 0,022 gram. Secara keseluruhan dari hasil kalibrasi kondisi timbangan tersebut masih dalam kondisi layak untuk digunakan.
\end{abstract}

Kata kunci : timbangan digital, nilai koreksi, ketidakpastian pengukuran.

Abstract: Balance digital is one of instrument much used at each posyandu case study this time occurring in posyandu puri gems bogor. With capacity $10 \mathrm{~kg}$ with accuracy 0,005 kilogram is often used to weigh toddlers residents .But was never testing calibration and verification performance at regular intervals, so that its accuracy the question. Hence in this research have been tried out undergone a calibration and measurement of uncertainty measurement of weight the digital .Test calibration covering the ability read weight, power repeated reading weight, deviation from value nominal scale, and tested influence position imposition not centered. From the calibration obtained that weight seca it has value correction lowest 4,9 grams in nominal imposition 1000 grams and the highest 45 grams in nominal imposition 10000 grams. Value of its role in taking measurements so much uncertainty about the $\pm 4,22$ grams and on the test and been approved the influence of the position of monitor the burden of similar properly and not only focus produce value could be a maximum of 0,022 the most ten grams of .Secured a second contract from the results of the calibration the condition of the scales of justice clear that there are still in a condition of worthy of to be used.

Keyword : balance digital, the value of correction, uncertainty of measurement.

\section{PENDAHULUAN}

Proses pengukuran merupakan kegiatan yang bertujuan untuk mendapatkan nilai suatu besaran. Kegiatan pengukuran mempunyai dampak yang luas terhadap ilmu pengetahuan, kehidupan pribadi manusia dan masyarakat dalam meningkatkan efisiensi. Kehidupan modern makin dicirikan oleh canggihnya perangkat untuk memperoleh data. Manusia modern makin bergantung kepada kegiatan mandapatkan data yang secara teknis dinamakan pengukuran. Dengan demikian manusia dapat memantau dan mengendalikan kehidupannya secara ketat dan efisien. Peranan pengukuran dalam kehidupan manusia semakin terasa vital dan imperatif ${ }^{[1]}$. 
Untuk mengukur diperlukan alat ukur. Alat ukur yang digunakan tergantung pada besaran ukur yang nilainya ingin diukur. Salah satu alat ukur yang vital adalah alat ukur timbang atau timbangan. Alat ukur timbang telah lama dipergunakan manusia dalam kehidupan sehari-hari, baik untuk perdagangan eceran maupun perdagangan besar. Kegiatan penimbangan bertujuan untuk mendapatkan nilai suatu besaran massa. Data-data yang didapatkan dari hasil penimbangan hanya merupakan estimasi. Estimasi hasil penimbangan masih mengandung keragu-raguan. Keragu-raguan yang diperoleh dari hasil pengukuran dapat diartikan sebagai nilai ketidakpastian. Ketidakpastian itu sendiri dapat diartikan ukuran reliabilitas suatu hasil pengukuran sehingga ketidakpastian menentukan mutu dari hasil pengukuran ${ }^{[2]}$.

Nilai ketidakpastian dapat diperoleh dengan cara mengkalibrasi alat ukur khususnya timbangan. Kalibrasi merupakan serangkaian kegiatan yang bertujuan menentukan kebenaran konvensional nilai penunjukan alat ukur dengan cara membandingkan terhadap standar ukur yang mampu tertelusur pada standar nasional maupun internasional. Hasil yang didapatkan dari kegiatan kalibrasi adalah mendapatkan kesalahan penunjukan, nilai pada tanda skala, faktor kalibrasi, atau faktor kalibrasi lainnya ${ }^{[3]}$.

\section{METODOLOGI}

Sebelum melakukan kalibrasi timbangan terlebih dahulu memeriksa kerataan posisi timbangan bisa menggunakan water pass. Periksa secara qualitatif kondisi fisik alat meliputi :

a. Badan dan permukaan : Periksa bagian luar dan kondisi kebersihan fisik, pastikan tidak ada bekas cairan atau benda asing lainnya diatas pan.

b. Display : Selama pengecekan fungsi, pastikan tampilan display berfungsi seluruhnya, yakinkan bahwa bagian tampilan display berfungsi.

c. Baterai : Periksa apakah indikator baterai menunjukkan baterai lemah, jika demikian ganti baterai.

\section{Teknik pengambilan data :}

a. Kondisikan ruangan pada temperatur $23^{\circ} \mathrm{C} \pm 2^{\circ} \mathrm{C}$, humidity $55 \% \pm 10 \%$.

b. Gunakan anak timbangan classes M1 dengan ukuran Kapasitas 1 kg, 2 kg, 2 kg, 5 kg.

c. Pengamatan penyimpangan (koreksi) dari pembacaaan nominal timbangan pada titik ukur 1.000 g, 2.000 g, 3.000 g, 4.000 g, 5.000 g, 6.000 g, 7.000 g, 8.000 g, 9.000 g, 10.000 g.

d. Pemeriksaan Efek Pembebanan Tidak di Pusat Pan pada titik ukur nominal $5.000 \mathrm{~g}$.

e. Perhitungan ketidakpastian penimbangan pada setiap titik ukur mulai 1.000 g sampai 10.000 g dan ketidakpastian penimbangan yang mewakili rentang ukur penimbangan pada tingkat kepercayaan $95 \%$.

f. Bentuk Pan dan posisi pengujian.

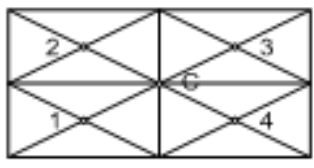

Gambar 1. Bentuk pan dan titik uji.

\section{HASIL DAN PEMBAHASAN}

Setelah dilakukan kalibrasi mengacu pada standar JCGM-100-2008 untuk timbangan digital milik Posyandu Puri Permata yang dilakukan di laboratorium massa PT.Global Kalibrasi Nusantara, tujuan untuk mengetahui nilai ketidakpastian suatu pengukuran. Timbangan digital yang digunakan merk Seca dengan kapasitas 10.000 g dengan resolusi pengukuran 5 g. Data yang diperoleh adri kalibrasi diolah menggunakan analisis ketidakpastian.

Angka pada kolom pembacaan alat merupakan hasil pengukuran kalibrasi ditambah nilai koreksi pada alat kalibrator (anak timbangan). Pada koreksi merupakan hasil pengurangan antara nilai standar dikurangi dengan nilai pembacaan. Dengan kata lain yang ada pada kolom pembacaan alat merupakan nilai aktual dari nilai nominal (standar). 
Tabel 1. Data pengukuran.

\begin{tabular}{|c|c|c|}
\hline $\begin{array}{c}\text { Nilai Nominal (Standar) } \\
(\mathbf{g})\end{array}$ & $\begin{array}{c}\text { Pembacaan alat } \\
(\mathbf{g})\end{array}$ & $\begin{array}{c}\text { Koreksi } \\
(\mathbf{g})\end{array}$ \\
\hline 1000 & 995,1 & 4,9 \\
\hline 2000 & 1993 & 7 \\
\hline 3000 & 2990 & 10 \\
\hline 4000 & 3980 & 20 \\
\hline 5000 & 4975 & 25 \\
\hline 6000 & 5970 & 30 \\
\hline 7000 & 6965 & 35 \\
\hline 8000 & 7965 & 35 \\
\hline 9000 & 8960 & 40 \\
\hline 10000 & 9955 & 45 \\
\hline
\end{tabular}

Tabel 2. Nilai koreksi kalibrator.

\begin{tabular}{|c|c|c|c|}
\hline Nominal & Koreksi & Kelas & Ketidakpastian \\
\hline $\mathbf{( k g )}$ & $\mathbf{( g )}$ & & $\mathbf{( \pm \mathbf { g } )}$ \\
\hline 1 & 0,090 & M1 & 0,27 \\
\hline 2 & 0,090 & M1 & 0,27 \\
\hline 2 & 0,100 & M1 & 0,27 \\
\hline 5 & 0,150 & M1 & 0,27 \\
\hline
\end{tabular}

Efek pembebanan tidak dipusat pan dihitung dengan rumus :

$$
u\left(I_{e c c}\right)=I\left[\Delta_{e c c-i}\right]_{\max } /\left(2 . L_{e c c} \sqrt{3}\right)
$$

Keterangan :

$\begin{array}{ll}I & =\text { rata-rata pembacaan } \\ L_{e c c} & =\text { massa nominal standar massa acuan } \\ {\left[\Delta_{e c c}-1\right]_{\max }} & =\text { nilai perbedaan maksimal efek pembebanan tidak dipusat pan }\end{array}$

Tabel.3. Nilai perbedaan maksimum.

\begin{tabular}{|l|c|c|}
\hline \multicolumn{1}{|c|}{ Posisi } & $\begin{array}{c}\text { Pembacaan } \\
\text { (g) }\end{array}$ & $\begin{array}{c}\text { Perbedaan Maksimum } \\
\text { (g) }\end{array}$ \\
\hline Tengah & 4.975 & \\
\hline Depan & 4.980 & \multirow{2}{*}{0,022} \\
\hline Belakang & 4.980 & \\
\hline Kiri & 4.980 & \\
\hline Kanan & 4.975 & \\
\hline
\end{tabular}

Dari perhitungan menggunakan rumus (1) nilai efek pembebanan tidak terpusat oleh pan, diambil dari 5 titik yang berbeda-beda dan mendapatkan hasil yang berbeda yang menghasilkan nilai perbedaan maksimum sebesar 0,022 gram. 
Tabel. 4. Rumus Budget Ketidakpastian [4].

\begin{tabular}{|c|c|c|c|c|c|}
\hline No. & Komponen & Distribusi & U & Pembagi & ui \\
\hline 1. & $\begin{array}{c}\text { Kemampuan Baca } \\
\text { Timbangan (Resolusi) }\end{array}$ & Triangular & $\mathrm{U}_{\mathrm{kbt}}$ & $\sqrt{6}$ & $\frac{1 / 2 \times \text { NST }}{\sqrt{6}}$ \\
\hline 2. & $\begin{array}{c}\text { Daya Ulang } \\
\text { Pembacaan }\end{array}$ & Normal & $\mathrm{U}_{\mathrm{rpt}}$ & $\sqrt{n}$ & $\left(\frac{\sigma_{\text {maks }}}{\sqrt{n}}\right)$ \\
\hline 3. & $\begin{array}{c}\text { Sertifikat Massa } \\
\text { Standar }\end{array}$ & Normal & $\mathrm{U}_{\mathrm{MC}}$ & $\mathrm{k}$ & $\frac{\text { Usertifikat }}{k}$ \\
\hline 5. & Bouyancy & Rectangular & $\mathrm{U}_{\text {by }}$ & $\sqrt{3}$ & $\frac{1 \text { ppm x nomin } a l}{\sqrt{3}}$ \\
\hline 6. & Efek Pembebanan & Rectangular & $\mathrm{U}_{\text {efek }}$ & $\sqrt{3}$ & $\frac{U_{\text {qfex }}}{\sqrt{3}}$ \\
\hline
\end{tabular}

Rumus pada Tabel.4 digunakan perhitungan secara berulang dari pembebanan $1 \mathrm{~kg}$ sampai $10 \mathrm{~kg}$, hasil dari masingmasing hitungan.

Tabel.5. Nilai budget ketidakpastian pada nominal $1 \mathrm{~kg}-9 \mathrm{~kg}$.

\begin{tabular}{|c|c|c|c|c|c|c|c|c|c|}
\hline Komponen & Satuan & Distribusi & $\mathbf{U}$ & Pembagi & $\mathbf{V i}$ & Ui & $\mathbf{C i}$ & $(\mathrm{UiCi})^{2}$ & $(\mathrm{UiCi})^{4} / \mathrm{Vi}$ \\
\hline $\begin{array}{l}\text { Kemampuan Baca } \\
\text { Timb. }\end{array}$ & g & Triangular & 2.5 & 2.449 & 50 & 1.02 & 1 & 1.04 & 0.02 \\
\hline Daya Ulang Pemb. & g & Normal & 2.415 & 1.414 & 9 & 1.71 & 1 & 2.92 & 0.95 \\
\hline Standar Massa & g & Normal & 0.016 & 2 & 200 & 0.01 & 1 & 0.00 & 0.00 \\
\hline Bouyancy & g & Rectangular & 0.001 & 1.732 & 200 & 0.00 & 1 & 0.00 & 0.00 \\
\hline Efek pembebanan & $\mathrm{g}$ & Rectangular & 0.002 & 1.732 & 50 & 0.00 & 1 & 0.00 & 0.00 \\
\hline $\mathrm{m}_{\text {Instability }}$ & $\mathrm{g}$ & Rectangular & 0.0050 & 1.732 & 50 & 0.00 & 1 & 0.00 & 0.00 \\
\hline \multicolumn{8}{|c|}{ Jumlah } & 3.96 & 0.97 \\
\hline \multicolumn{8}{|c|}{ Ketidakpastian baku gabungan, uc, $g$} & \multicolumn{2}{|r|}{1.99} \\
\hline \multicolumn{8}{|c|}{ Derajat kebebasan efektif, Veff } & \multicolumn{2}{|c|}{16.21} \\
\hline \multicolumn{8}{|c|}{ Faktor cakupan, $k$ untuk Veff \& CL 95\% } & \multicolumn{2}{|r|}{2.12} \\
\hline \multicolumn{8}{|c|}{ Ketidakpastian bentangan, $U=k . U c, g$} & \multicolumn{2}{|r|}{4.21} \\
\hline
\end{tabular}

Tabel.6. Nilai budget ketidakpastian pada nominal $10 \mathrm{~kg}$.

\begin{tabular}{|c|c|c|c|c|c|c|c|c|c|}
\hline Komponen & Satuan & Distribusi & $\mathbf{U}$ & Pembagi & $\mathbf{V i}$ & Ui & $\mathbf{C i}$ & $(\mathrm{UiCi})^{2}$ & $(\mathrm{UiCi})^{4} / \mathrm{Vi}$ \\
\hline $\begin{array}{l}\text { Kemampuan Baca } \\
\text { Timb. }\end{array}$ & g & Triangular & 2.5 & 2.449 & 50 & 1.02 & 1 & 1.04 & 0.02 \\
\hline Daya Ulang Pemb. & $\mathrm{g}$ & Normal & 2.415 & 1.414 & 9 & 1.71 & 1 & 2.92 & 0.95 \\
\hline Standar Massa & $\mathrm{g}$ & Normal & 0.16 & 2 & 200 & 0.0800 & 1 & 0.01 & 0.00 \\
\hline Bouyancy & $\mathrm{g}$ & Rectangular & 0.01 & 1.732 & 200 & 0.01 & 1 & 0.00 & 0.00 \\
\hline Efek pembebanan & g & Rectangular & 0.002 & 1.732 & 50 & 0.00 & 1 & 0.00 & 0.00 \\
\hline $\mathrm{m}_{\text {Instability }}$ & g & Rectangular & 0.05 & 1.732 & 50 & 0.03 & 1 & 0.00 & 0.00 \\
\hline \multicolumn{8}{|l|}{ Jumlah } & 3.97 & 0.97 \\
\hline \multicolumn{8}{|c|}{ Ketidakpastian baku gabungan, uc, $g$} & \multicolumn{2}{|c|}{1.99} \\
\hline \multicolumn{8}{|c|}{ Derajat kebebasan efektif, Veff } & \multicolumn{2}{|c|}{16.26} \\
\hline \multicolumn{8}{|c|}{ Faktor cakupan, $k$ untuk Veff \& CL 95\% } & \multicolumn{2}{|r|}{2.12} \\
\hline \multicolumn{8}{|c|}{ Ketidakpastian bentangan, $U=k . U c, g$} & \multicolumn{2}{|r|}{4.22} \\
\hline
\end{tabular}


Untuk mengetahui nilai ketidakpastian bentangan pada tingkat kepercayaan 95\% menggunakan rumus (2) dengan faktor cakupan $\mathrm{k}=2^{[5]}$.

$$
\begin{aligned}
U_{95} & = \pm \mathrm{k} . \mathrm{Uc} \\
= & \pm \mathrm{k} . \quad \sqrt{\left(U_{k b t}\right)^{2}+\left(U_{r p t}\right)^{2}+\left(U_{M C}\right)^{2}+\left(U_{b y}\right)^{2}+\left(U_{m-i n s t}\right)^{2}} \\
& =4,22 \text { gram. }
\end{aligned}
$$

Keterangan :

$\begin{array}{ll}U_{k b t} & =\text { ketidakpastian kemampuan baca timbangan bayi. } \\ U_{r p t} & =\text { ketidakpastian daya ulang pembacaan. } \\ U_{M C} & =\text { ketidakpastian standar dari massa standar. } \\ U_{b y} & =\text { ketidakpastian pengaruh bouyacy. } \\ U_{m-\text {-inst }} & =\text { ketidakpastian instability massa standar. }\end{array}$

Dari hasil kalibrasi dan analisis secara matematis dengan tingkat kepercayaan 95\% dengan faktor cakupan 2 mendapatkan nilai $\pm 4,22$ gram. Artinya parameter hasil ukur yang diberikan memberikan sebaran nilai-nilai yang secara layak dapat diberikan pada besaran ukur. Jadi pada nilai pembacaan alat unit under test akan dikurangi atau ditambah nilai ketidakpastian, nilai $\quad \pm 4,22$ gram merupakan nilai interval dari nilai sebenarnya (aktual).

\section{KESIMPULAN}

Timbangan digital milik Posyandu Puri Permata Bogor dengan kapasitas $10 \mathrm{~kg}$ dan mempunyai tingkat akurasi 5 gram, setelah dilakukan kalibrasi ulang mengacu pada JCGM-100-2008 mendapat nilai ketidakpastian \pm 4,22 gram. Jika misalkan pembebanan atau nominal dengan nilai 1000 gram nilai pembacaan 1004,22 gram sampai 995,78 gram. Pada uji pembebanan titik tidak terpusat pada 5 titik pan yang dipengaruhi efek tidak terpusat memperoleh perbedaan maksimum 0,022 gram. Dari hasil analisa ketidakpastian dan efek pembebanan tidak dipusat kondisi timbangan tersebut masih dalam kondisi layak untuk digunakan.

\section{DAFTAR PUSTAKA}

[1] Ibrahim, T, 1998, Peneraan Timbangan Buku-1. Widyasiswara Utama Pratama: Bandung.

[2] Subeno. E, 2009, Ketidakpastian Pengukuran. Balai metrologi Semarang: Semarang.

[3]KAN, 2003, Pedoman Evaluasi dan Pelaporan Ketidakpastian Pengukuran. http://pphp.deptan.go.id/layanan_informasi/mutu_dan_standarisasi/lainlain/codex_allimentarious_commission/k anLIPI 2008. Pelatihan dan Teknik Pengukuran Massa. UPT Balai Pengembangan Instrumentasi: Bandung.

[4] David B.Prowse, 1986, The Calibration of Balances, Commonwealth Scientific and Industrial Research Organization (CSIRO): Australia.

[5] JCGM 100: 2008, Evaluation of measurement data - Guide to the expression of Uncertainty inMeasurement, First Edition September 2008. 